\title{
Safety and effectiveness of introducing a robotic-assisted percutaneous coronary intervention program in a tertiary center: a prospective study
}

\author{
Pedro A. Lemos^, Marcelo Franken^, Jose Mariani Jr^, Adriano Caixeta^, Breno O. Almeida^, \\ Fabio G. Pitta, Guy F. A. Prado^, Stefano Garzon^, Felipe Ramalho, Gabriel Albuquerque, \\ Ivanise M. Gomes, Irisvaldo S. de Oliveira, Leonardo Valle^, Leonardo Galastri^^, Breno B. Affonso, \\ Felipe Nasser, Rodrigo G. Garcia^ ${ }^{\wedge}$
}

Interventional Cardiology Department, Hospital Israelita Albert Einstein, Sao Paulo, Brazil

Contributions: (I) Conception and design: PA Lemos; (II) Administrative support: M Franken; (III) Provision of study materials or patients: M Franken, FG Pitta; (IV) Collection and assembly of data: PA Lemos; (V) Data analysis and interpretation: PA Lemos; (VI) Manuscript writing: All authors; (VII) Final approval of manuscript: All authors.

Correspondence to: Pedro A. Lemos, MD, PhD. Interventional Cardiology Department, Hospital Israelita Albert Einstein, Av. Albert Einstein, 627. São Paulo, SP 05652-900, Brazil. Email: pedro.lemos@einstein.br.

Background: Robotic-assisted percutaneous coronary intervention (PCI) is a novel technology that permits remote operation of interventional devices. However, little is known about the safety and effectiveness of introducing a robotic PCI program in a hospital already experienced in traditional coronary angioplasty.

Methods: Prospective single-arm survey to assess the safety and effectiveness of robotic-assisted PCI in comparison to pre-defined performance goals. The study cohort comprised all consecutive cases treated with robotic PCI since its introduction. The safety primary endpoint was a composite of (I) overall death or (II) non-fatal adverse events related to target vessel complications (stent thrombosis, myocardial infarction, vessel perforation or cardiac tamponade, or repeat invasive treatment) during the index hospitalization. The efficacy primary endpoint was robotic-assisted procedural success, a composite of (I) successful dilatation of the target lesion and (II) successful robotic assistance, defined as absent non-planned manual conversion.

Results: A total of 83 patients and 112 lesions were prospectively enrolled. The rate of angiographic success was $99.1 \%$. From these, 97 lesions $(86.6 \%)$ were treated with only robotic PCI or with hybrid according to the pre-interventional plan. The rates of efficacy and safety primary endpoints were $85.7 \%$ and $2.4 \%$ respectively $(\mathrm{P}<0.01$ for non-inferior to the pre-defined performance threshold).

Conclusions: Introduction of robotic-assisted PCI in a tertiary center was associated with safe and effective results, comparable to pre-defined goals of optimal performance.

Keywords: Coronary; robotics; noninferiority; angioplasty; stent

Submitted Jul 17, 2021. Accepted for publication Sep 29, 2021.

doi: $10.21037 / \mathrm{cdt}-21-442$

View this article at: https://dx.doi.org/10.21037/cdt-21-442

\footnotetext{
^ ORCID: Pedro A. Lemos, 0000-0002-6782-750X; Marcelo Franken, 0000-0002-4286-8559; Jose Mariani Jr, 0000-0002-0332-7530; Adriano Caixeta, 0000-0002-6287-5414; Breno O. Almeida, 0000-0003-4436-7245; Guy F. A. Prado, 0000-0002-6942-355X; Stefano Garzon, 0000-00025705-4865; Leonardo Valle, 0000-0001-6255-340X; Leonardo Galastri, 0000-0001-9599-3778; Rodrigo G. Garcia, 0000-0002-1968-9595.
} 


\section{Introduction}

Percutaneous coronary intervention (PCI) is an established and mature method, applied worldwide according to the same technical principles, which traditionally frame the procedure as a manual one, performed by physicians who must stand at the patients' side for the whole duration of the operation. Coronary interventions are guided by fluoroscopic imaging, therefore exposing to ionizing radiation the healthcare team, who must wear heavy and non-ergonomic protection equipment. Altogether, this whole description is of a relatively unhealthful professional space that has been associated with the risk of malignancies, cataracts, orthopedic problems, and other medical complications (1-4).

Recently, a robotic-assisted system for PCI has been developed to overcome those limitations (5-11). With this technology, guide-catheters, guidewires, and interventional devices are operated through a robotic arm, remotely maneuvered by an interventionalist using joysticks and touchscreens from a control cockpit. The novel tool has been previously validated, showing marked reduction in the need of physical closeness between the healthcare team and the operating table $(12,13)$, and thus in radiation exposure (5-11).

The robotic-assisted PCI platform is currently approved for clinical use in Japan, the United States, Europe, and, recently, Brazil. Nevertheless growing in adoption, the technology is only debuting in practice and relatively few studies have been conducted to prospectively assess its clinical impact. In particular, little is known about the safety and effectiveness of initiating a robotic PCI program in a hospital already experienced in traditional coronary angioplasty.

That was the context under which the present prospective study was conceived, therefore designed to assess the performance of robotic-assisted PCI upon its introduction in a tertiary and highly specialized center of invasive cardiology.

We present the following article in accordance with the Transparent Reporting of Evaluations with Nonrandomized Designs (TREND) and the MDAR reporting checklists (available at https://cdt.amegroups.com/article/ view/10.21037/cdt-21-442/rc).

\section{Methods}

\section{Study design and patient population}

We conducted a prospective single-arm survey to assess the safety and effectiveness of starting a robotic-assisted PCI program in a single tertiary center, evaluating the results of all procedures utilizing the new technology in comparison to pre-defined performance goals.

The study cohort comprised all consecutive cases treated with robotic PCI since its introduction. The population consisted of patients with either chronic or acute coronary artery disease requiring PCI. One or more lesions could be treated the index procedure, but all of them must have planned robotic manipulation in at least one step during the procedure. Patients with ST-segment elevation myocardial infarction $<48$ hours or indication of emergent procedures were not included, as well as patients with any invasive cardiac or non-cardiac treatment scheduled within the first month after the index procedure. Also, patients with angiographic thrombus, unprotected left coronary artery (stenosis $>50 \%$ ), total occlusion (thrombolysis in myocardial infarction 0 or 1 anterograde flow), or target lesion in a surgical graft were not included.

The occurrence of adverse events was prospectively assessed during the index hospitalization and for 30 days after the robotic intervention. The protocol was approved by the institutional review board of Hospital Israelita Albert Einstein, Sao Paulo-SP, Brazil and by the National Commission of Ethics in Research (CAAE: 96392318.4.0000.0071), Brasília-DF, Brazil and the study was conducted in the Declaration of Helsinki (as revised in 2013). Signed, written, informed consent was obtained from every patient.

\section{Robotic-assisted PCI}

\section{Description of the system}

Robotic PCI was performed using the CorPath GRX Robotic System (Corindus, A Siemens Healthineers Company, Waltham, MA, USA), which is a robotic platform developed for assistance of percutaneous coronary or vascular procedures. The system allows controlling of guide-catheters, permitting engagement/disengagement of the catheter in the coronary ostium, as well as advanced finesse moves such as deep coronary intubation, if needed. Also, the robotic system permits the delicate maneuvering of 0.014 " guidewires with submillimetric exactitude, as well are of rapid-exchange balloons and stents.

As described elsewhere, the system comprises two principal modules (Figure 1). The first is a cockpit, from which the operator maneuvers the interventional devices using joystick and touchscreen controls, having full control 

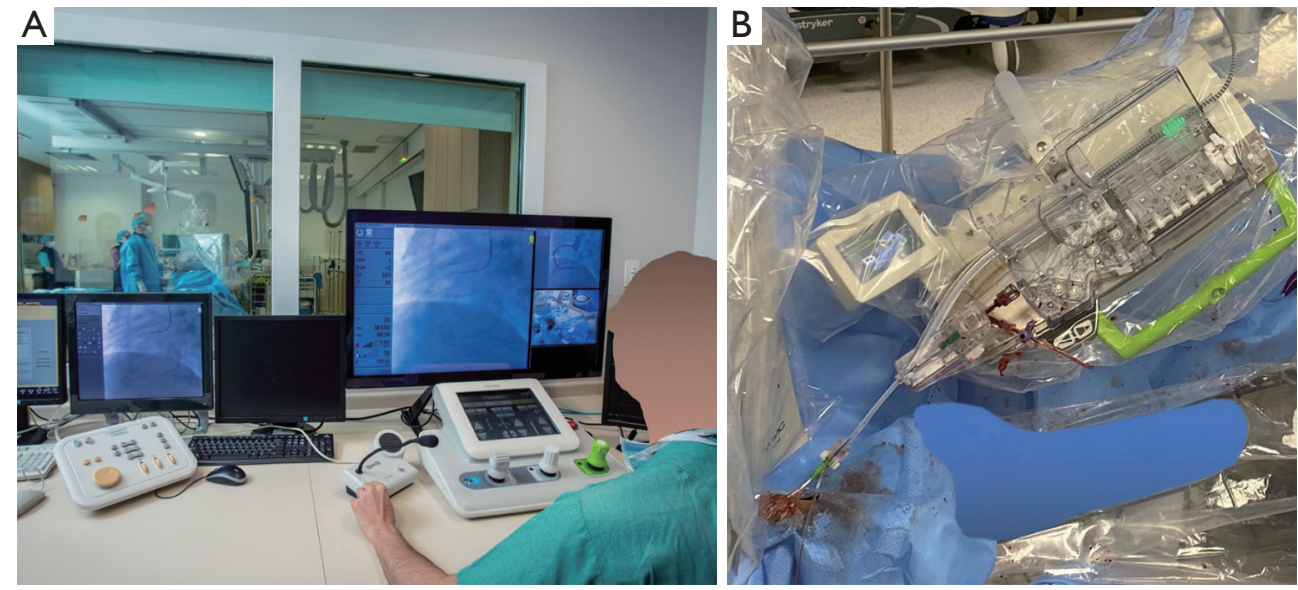

Figure 1 Overview of the two modules of the CorPath GRX Robotic System (Corindus, A Siemens Healthineers Company, Waltham, MA, USA). (A) Control cockpit, from which the interventionalist operates the interventional devices through joysticks and a computerized touchscreen. Note that the operator performs the procedure sitting and unscrubbed outside of the suite, while having full view of the navigation, imaging, and other important patient, as well as maintaining visual contact with the inside space, through the cath lab leaded glass window. (B) The robotic arm itself, located at tableside, which houses a sterile single-use cassette that provides the interface for insertion of the interventional devices.

of the navigation, imaging, and other important patient and procedural information through high-definition monitors and a roof camera (Figure 1). In our study, the cockpit was positioned outside of the catheterization suite, where the operator could perform the procedure sitting and unscrubbed, while still having visual contact with the inside of the suite, through the cath lab leaded glass window (Figure 1). The other module is the robotic arm itself, located at tableside, which houses a sterile singleuse cassette that provides the interface through which the inserted interventional devices are robotically commanded (Figure 1). In the present version, the cockpit and tableside unit are connected by communication cabling with no wifi connection needed. The clinical use of the robotic system is approved by regulatory agencies in many countries (e.g., Conformité Européenne mark, Food and Drug Administration, Japan, and Brazil among others).

Two important features of the robotic system used in our study are that (I) the interventional devices utilized are the same as in traditional PCI and (II) connection and disconnection of the robotic arm is an easy action that can be accomplished immediately without having to retrieve any interventional device already in place. These characteristics make the system readily adaptable to the routine practice, making conversion to manual as well as planned hybrid operations (i.e., part of the procedure performed robotically, part manually) straightforward to implement.

\section{Robotic-assisted PCI}

Vascular access, insertion of guide-catheters was performed manually as usual care, entirely left at the discretion of the operator. Only after engagement of the coronary ostium the robotic assistance begins, allowing for manipulation of 0.014 " guidewires, balloons, and stents, which are remotely controlled by operators outside the room through a control panel. Additionally, robotic manipulation of the guidecatheter is also possible, permitting small positioning adjustments. Exchanges of materials (e.g., balloons, stents) during the procedure are performed by the interventional staff. In our study, both total and hybrid robotic-assisted PCI were allowed. However, the operator had to inform prior to the initiation of the procedure which strategy would be used. Also, for those undergoing planned hybrid roboticassisted PCI, the interventionalist was asked to annotate, before the beginning of the intervention, which steps were intended for manual or robotic manipulation.

\section{Training and education plan}

After the system was installed in the hospital, before the first patient was treated, the whole team of interventionalists (five fully certified interventional cardiologists with a minimum of 20 years of experience in manual PCI), together with six registered nurses, and seven cath lab technicians were extensively exposed to the functioning details of the equipment, in a training and education program provided 
by the manufacturer, conducted at the hospital. Users assigned to operate sterile parts received specific didactic and hands-on training directed to operating the singleuse cassettes, removing and changing balloons, stents, and guidewires. The interventionalists attended didactic sessions and performed hands-on training on a bench-top model, with verbal guidance and evaluation from a member of Corindus clinical staff. A post-training quiz was then applied and needed to be successfully answered in at least 8 from the 10 questions. Then, in the following days, five actual cases were treated with robotic PCI by the local team, under supervision. The training schedule was delivered in person by a non-physician specialist who conducted the sessions and observed the execution of those first cases.

After this first phase, cases started to be regularly performed without supervision. Two months afterwards, a new visit of the manufacturer's clinical staff was accomplished to assess the adequacy of the operation and last certify the site.

\section{Study endpoints}

\section{Safety primary endpoint}

A composite of (I) overall death or (II) non-fatal adverse events related to target vessel complications [stent thrombosis (definite or probable), myocardial infarction, vessel perforation (Ellis' grade III or III-cavity spilling) or cardiac tamponade, or non-planned invasive treatment] during the index hospitalization, as a per patient analysis (14-16).

\section{Efficacy primary endpoint}

Robotic-assisted procedural success, a composite of (I) successful dilatation of the target lesion with residual diameter stenosis $<30 \%$ and (II) successful robotic assistance, defined as non-manual conversion (i.e., fully accomplished robotic operation) of any interventional step intended to be robotic according to the pre-procedural strategy planning, as a per lesion analysis.

\section{Statistical analyses}

\section{Performance goals and statistical considerations}

This exploratory, single-arm, study was designed to assess the safety and effectiveness of robotic-assisted PCI in a newly initiated program in a tertiary center, with the study cohort comprising all consecutive cases treated with the novel technology since its introduction. The performance of robotic PCI was measured up against pre-defined goals, which were used as indicators to evaluate whether the new procedure is non-inferiority compared traditional manual PCI.

The safety and efficacy primary endpoints were powered separately and the largest sample size from the two calculations was ultimately chosen as the final sample size for the study. From historical series, assuming a mixedprofile population, the following incidences were considered for each component of the composite safety endpoint, as a per patient analysis: (I) overall death $0.0-4.5 \%(17-23)$; (II) definite or probable stent thrombosis $0.0-3.3 \%$ (17,21,24-26); (III) myocardial infarction $0.0-3.0 \%$ $(20,25,27)$; (IV) vessel perforation (Ellis' grade III or IIIcavity spilling) or cardiac tamponade $0.4 \%(28,29)$; (V) unplanned invasive treatment $0.5 \%$ (20). Based on those figures, the goal rate of the safety composite primary endpoint was guessed at $5 \%$ with an upper value of $12 \%$ at maximum. A sample size of 83 was calculated as sufficient to test whether the results were not inferior to the safety performance goal upper threshold, with a power of $90 \%$ and a one-sided alpha of 0.05 .

The rate of the efficacy primary endpoint (roboticassisted procedural success) was estimated as $85 \%$, which was then arbitrarily adjusted downward by $15 \%$ $(5,6,10,30,31)$, resulting in a performance goal of $70 \%$. Accordingly, we calculated that 49 treated lesions would be needed to assess whether the results of the newly introduced robotic-assisted PCI program were not lower than the efficacy performance goal threshold, with a $10 \%$ power and an alpha of 0.05 .

Therefore, a final sample size of 83 patients ultimately comprised the cohort of the present study.

Continuous variables are expressed as mean \pm standard deviation and categorical variables are expressed as frequencies and percentages. Single-sample one-tailed binomial $95 \%$ confidence interval for safety and efficacy primary endpoints were estimated by the Clopper-Pearson method. Confirmatory analyses were performed with Jeffreys, Wald, Wilson, and Agresti-Coull methods and provided similar results. All analyses were performed with SPSS 21.0 statistical package (SPSS, Chicago, IL, USA) and Stata/SE 14.1 for Windows (StataCorp LP. College Station, TX, USA), and $\mathrm{P}$ values $<0.05$ were considered to indicate statistical significance. 


\section{Results}

The robotic-assisted program was initiated in June 2019 and the last patient of this survey was enrolled in November 2020, summing up a cohort of 83 consecutive patients treated with the new technique. On average, patients aged $60.7 \pm 8.6$ years, $25.3 \%$ were women, $36.1 \%$ were diabetics, and approximately half of the population presented with acute coronary syndromes (Table 1).

A total of 112 target lesions were treated, with half of lesions presenting at least one angiographic characteristic of high complexity (Table 1). Angiographic success was achieved in $99.1 \%$ (111 lesions), and 86.6\% (97 lesions) were treated exclusively through robotic PCI or planned hybrid PCI (i.e., planned robotic plus manual PCI) (Table 2). Robotic-assisted procedural success (i.e., angiographic success accomplished with robotic PCI as planned)the efficacy primary endpoint, was reached in 96 lesions $(85.7 \%)$ (Table 2$)$. The rate was numerically higher than the estimated success rate of $85 \%$ and the lower $95 \%$ confidence interval $(76.7 \%)$ was non-inferior to the predefined performance goal (Figure 2).

Table 3 summarizes the reasons for unplanned manual switch during robotic-assisted PCI (14 patients; 15 lesions). Inability to advance the interventional devices (0.014" guidewire, balloon, or stent) until or across the lesion represented a large proportion of cases of failed robotic manipulation.

A total of 2 patients $(2.4 \%)$ presented fatal or target vessel-related complications during the index hospitalization (safety primary endpoint) (Table 4). This incidence was numerically lower than the expected rate of $5 \%$, and the respective $95 \%$ confidence interval (9.4\%) was non-inferior to the pre-defined performance threshold (Figure 2).

After 30 days of follow-up, the outcomes remained uneventful except by a case of sudden death after discharge (which was also classified as probable stent thrombosis) (Table 4).

As an appraisal of the potential effect of a "learningcurve" for the new robotic PCI, the comparative demographics, angiographic characteristics, interventional strategy, and clinical results between the first 42 patients and the last 41 patients included are depicted in Table 5.

\section{Discussion}

The present study demonstrated that robotic-assisted PCI can be performed safely and effectively just after its introduction in a tertiary center, associated with a $2.4 \%$ rate of in-hospital adverse events and an $87.5 \%$ success rate that significantly reached anticipated performance levels by preestablished goals.

As previously shown by other groups and ours, roboticassisted PCI undeniably provides distancing between the interventionalist and the tableside, producing a muchimproved work environment regarding radiation exposure, procedural ergonomics, orthopedic protection, and interpersonal air sharing (5-13). Notwithstanding the fact that those are valuable benefits, in order to be fully and largely adopted, the novel technology must be proven functional and reliable, without compromising the already good clinical results achieved with traditional manual intervention. Our cohort, composed of young patients with acute coronary syndromes, presented a low mean average SYNTAX score, which reflects a modest disease extension but may not entirely describe the level of anatomical complexity of the target lesions. In fact, half of the patients presented at least one feature of angiographic complexity of the treated segment. Our findings suggest that robotic PCI is a safe and effective procedure, maintaining the expected high levels of clinical performance even as shortly as upon its introduction.

In our study, the vast majority of cases were accomplished through robotic manipulation. However, a small, though sizable proportion of cases, approximately $15 \%$, needed unplanned manual aid during the procedure. Our findings cannot directly answer whether those events reflect an inherent limitation of the technology or, alternatively, if it is related to the current point in the learning curve our team is, or a combination of both. Nevertheless, the present findings convincingly indicate robotic assistance has the potential to be used as a mainstay tool, applicable to a large number of patients undergoing percutaneous interventions.

The collection of the present cohort completely encompasses the learning curve of our group with the new technology. Curiously, we were not able to demonstrate a clear-cut difference in the profile of patients and results of procedures between the first half and the last half of the population. It is important to mention that the study was not designed for this purpose and therefore does not have statistical power to differentiate this situation. On the other hand, it is noteworthy that the team comprised a highly experienced group of interventionalists, nurses, and technicians who rapidly embraced robotic-PCI, something that might have damped the learning curve. Robotic-PCI seemed to be easily implemented to the daily practice of a 
Table 1 Baseline and angiographic characteristics (83 patients; 112 lesions)

\begin{tabular}{|c|c|}
\hline Characteristics & Value \\
\hline Age, years & $60.7 \pm 8.6$ \\
\hline Male sex & $61(73.5)$ \\
\hline Weight, kg & $79.4 \pm 13.5$ \\
\hline Height, cm & $167.9 \pm 8.4$ \\
\hline Hypertension & $75(90.4)$ \\
\hline Current smoker & $34(41.0)$ \\
\hline Diabetes mellitus & $30(36.1)$ \\
\hline Peripheral artery disease & $2(2.4)$ \\
\hline Previous stroke & $2(2.4)$ \\
\hline Previous myocardial infarction $>1$ month & $22(26.5)$ \\
\hline Previous coronary surgery & $1(1.2)$ \\
\hline Previous $\mathrm{PCl}$ & $34(41.0)$ \\
\hline End-stage renal dysfunction & $1(1.2)$ \\
\hline \multicolumn{2}{|l|}{ Clinical presentation } \\
\hline Asymptomatic & $14(16.9)$ \\
\hline Stable angina & $26(31.3)$ \\
\hline Acute coronary syndrome & $41(49.4)$ \\
\hline Recent ST-elevation myocardial infarction & $7(17.0)$ \\
\hline Electrocardiographic changes & $27(65.9)$ \\
\hline Elevated biomarkers & $33(80.5)$ \\
\hline Other & $2(2.4)$ \\
\hline \multicolumn{2}{|l|}{ Treated vessel } \\
\hline Left main coronary & $1(0.9)^{*}$ \\
\hline Left anterior descending & $37(33.0)$ \\
\hline Diagonal & $10(8.9)$ \\
\hline Left circumflex & $22(19.6)$ \\
\hline Obtuse marginal & $11(9.8)$ \\
\hline Ramus intermedius & $1(0.9)$ \\
\hline Right coronary artery & $30(26.8)$ \\
\hline In-stent restenosis & $11(9.8)$ \\
\hline SYNTAX score & $11.0 \pm 7.0$ \\
\hline \multicolumn{2}{|l|}{ Lesion type } \\
\hline $\mathrm{A} / \mathrm{B} 1$ & $25(22.3)$ \\
\hline B2 & $21(18.8)$ \\
\hline C & $66(58.9)$ \\
\hline
\end{tabular}

Table 1 (continued)
Table 1 (continued)

\begin{tabular}{lc}
\hline Characteristics & Value \\
\hline Complexity characteristics & \\
Moderate or severe calcification & $21(18.8)$ \\
Moderate or severe tortuosity & $25(22.3)$ \\
Lesion angulation $>45^{\circ}$ & $27(24.1)$ \\
True bifurcation & $22(19.6)$ \\
Aorto-ostial lesion & $4(3.6)$ \\
Any of the above & $56(50.0)$ \\
\hline
\end{tabular}

Numbers are mean \pm standard deviation or counts (percentages). *, a lesion originally located in proximal left descending artery which was treated with stenting extending to the distal left main coronary. $\mathrm{PCl}$, percutaneous coronary intervention.

Table 2 Robotic-assisted PCI-procedural characteristics (83 patients; 112 lesions)

\begin{tabular}{lc}
\hline Characteristics & Value \\
\hline Access site & \\
$\quad$ Right radial artery & $70(84.3)$ \\
$\quad$ Right femoral artery & $15(18.1)$ \\
Intravascular ultrasound guidance & $18(21.7)$ \\
Contrast volume, mL & $206.4 \pm 114.4$ \\
Procedure duration, minutes ${ }^{\dagger}$ & $86.5 \pm 49.2$ \\
Lesions treated per patient & $1.4 \pm 0.6$ \\
Stents implanted per patient & $1.8 \pm 1.0$ \\
Summed length of stent per patient & $49.9 \pm 29.8$ \\
Lesions with angiographic success & $111(99.1)$ \\
Robotic assistance & \\
Lesions treated exclusively with robotic PCl $^{\text {Lesions treated with at least one robotic step as }}$ & $92(82.1)$ \\
planned & \\
Lesions treated with at least one unplanned & $15(13.4)$ \\
manual step $_{\text {Robotic-assisted procedural success }}^{\S}$ & $96(85.7)$ \\
\hline
\end{tabular}

Numbers are mean \pm standard deviation or counts (percentages). *, the sum does not equal $100 \%$ because of multiple vascular access was needed in some patients; ${ }^{\dagger}$, from guiding catheter insertion time to removal time; ${ }^{\ddagger}$, planned hybrid PCl; ${ }^{\S}$, efficacy primary endpoint (angiographic success and successful robotic assistance performed as planned). $\mathrm{PCl}$, percutaneous coronary intervention. 

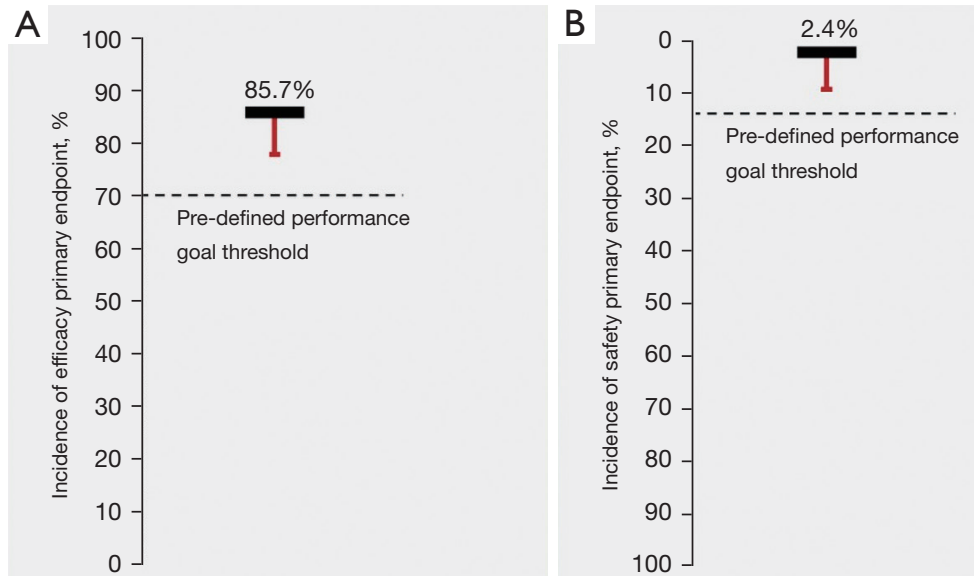

Figure 2 Safety and efficacy primary endpoints. Observed rates of efficacy (A) and safety (B) primary endpoints are represented by the black horizontal bars. Error bars (red) represent $95 \%$ confidence limits, and the dotted black line indicates the pre-defined performance goals (12\% for the safety and $70 \%$ for the efficacy primary endpoints respectively). Note that error bars of safety and efficacy do not cross the dotted black lines indicating the performance goals $(\mathrm{P}<0.01$ for noninferiority, for both endpoints).

Table 3 Unplanned manual switch during robotic-assisted PCI (14 patients; 15 lesions)

\begin{tabular}{lc}
\hline Parameters & Value \\
\hline Reasons for unplanned manual switch* & \\
Inability to advance until the lesion as intended & $6(40.0)$ \\
0.014" guidewire & $3(20.0)$ \\
Balloon & $2(13.3)$ \\
Stent & $2(13.3)$ \\
Inability to cross the lesion as intended & $2(13.3)$ \\
0.014" guidewire & $1(6.7)$ \\
Balloon & 0 \\
$\quad$ Stent & $1(6.7)$ \\
Inability to retrieve the interventional device as & 0 \\
intended & \\
Inability to remotely manipulate the as intended & 0 \\
Device malfunction & $1(6.7)$ \\
Clinical condition which required rapid medical & $2(13.3)$ \\
intervention & \\
Other reasons for unplanned manual switch & $4(26.7)$ \\
Successful unplanned manual switch & $15(100.0)$ \\
\hline
\end{tabular}

Numbers are counts (percentages) per lesion. *, the sum does not equal $100 \%$ because of multiple reasons occurred in some cases. $\mathrm{PCl}$, percutaneous coronary intervention.
Table 4 In-hospital and 30-day clinical outcomes (83 patients; 112 lesions)

\begin{tabular}{|c|c|}
\hline Outcomes & Value \\
\hline \multicolumn{2}{|l|}{ In-hospital } \\
\hline Death & 0 \\
\hline Stroke & $1(1.2)$ \\
\hline Target vessel-related complications & $2(2.4)$ \\
\hline Myocardial infarction & $1(1.2)$ \\
\hline Vessel perforation or cardiac tamponade* & 0 \\
\hline Repeat intervention & $1(1.2)$ \\
\hline Stent thrombosis & 0 \\
\hline Death or target vessel-related complications ${ }^{\dagger}$ & $2(2.4)$ \\
\hline \multicolumn{2}{|l|}{ Cumulative 30-day } \\
\hline Death & $1(1.2)$ \\
\hline Stroke & $1(1.2)$ \\
\hline Myocardial infarction & $1(1.2)$ \\
\hline Repeat intervention & $1(1.2)$ \\
\hline Stent thrombosis & $1(1.2)$ \\
\hline Definite & 0 \\
\hline Probable & $1(1.2)$ \\
\hline Possible & 0 \\
\hline
\end{tabular}

Numbers are counts (percentages). *, Ellis' grade III or IIIcavity spilling; ${ }^{\dagger}$, safety primary endpoint: death or non-fatal stent thrombosis (definite or probable), myocardial infarction, vessel perforation (Ellis' grade III or III-cavity spilling) or cardiac tamponade, or non-planned invasive treatment. 
Table 5 Demographics, angiographic and results between the first 42 patients and the last 41 patients included

\begin{tabular}{|c|c|c|c|}
\hline Parameters & First 42 patients (56 lesions) & Last 41 patients (56 lesions) & $P$ value \\
\hline Male sex & $31(73.8)$ & $30(73.2)$ & 0.6 \\
\hline Diabetes mellitus & $14(33.3)$ & $16(39.0)$ & 0.4 \\
\hline Acute coronary syndrome & $24(57.1)$ & $17(41.6)$ & 0.1 \\
\hline Lesion type B2/C & $47(83.9)$ & $40(71.4)$ & 0.2 \\
\hline \multicolumn{4}{|l|}{ Complexity characteristics } \\
\hline Moderate or severe calcification & $10(18.2)$ & $11(19.6)$ & 0.5 \\
\hline Moderate or severe tortuosity & $14(25.0)$ & $11(19.6)$ & 0.3 \\
\hline Aorto-ostial lesion & $2(3.6)$ & $2(3.6)$ & $>0.9$ \\
\hline Any of the above & $28(50.0)$ & $28(50.0)$ & $>0.9$ \\
\hline Contrast volume, $\mathrm{mL}$ & $190.8 \pm 101.5$ & $222.4 \pm 125.6$ & 0.2 \\
\hline Procedure duration, minutes & $75.9 \pm 37.0$ & $97.4 \pm 57.6$ & 0.046 \\
\hline Lesions treated per patient & $1.3 \pm 0.5$ & $1.4 \pm 0.6$ & 0.5 \\
\hline Summed length of stent per patient & $48.4 \pm 27.3$ & $50.1 \pm 32.2$ & 0.8 \\
\hline Efficacy primary endpoint & $48(85.7)$ & $48(85.7)$ & $>0.9$ \\
\hline Safety primary endpoint & 0 & $2(4.9)$ & 0.2 \\
\hline
\end{tabular}

Numbers are mean \pm standard deviation or counts (percentages).

busy catheterization laboratory.

The present findings, however, are confined to the conditions investigated in the study and cannot be extrapolated to further clinical scenarios, such as the treatment of emergency patients or highly complex lesions subsets. The results of robotic-PCI, as well as the potential learning curve for those subsets, cannot be assessed from the present study. Moreover, the promising results of initiating a robotic-PCI program observed in our relatively small, single-arm, single-center trial may not entirely reflect the conditions of other institutions. Additionally, it must be acknowledged that known restrictions of robotic-PCI, in its current stage of technological development, were not tested, such as the utilization of over-the-wire devices. Finally, as all new technology, robotic-PCI may result in additional costs essentially at early stages of the method. However, we believe that a more widespread use can reduce the current costs of the procedure and if the development of the method beats the safety and efficacy results of conventional coronary angioplasty, especially for more complex cases, it will be cost effective in the most of the procedures.

It is our perception that a full and comprehensive utilization of the technology at its highest interventional capacity might require longer and continued use, most probably coupled with a change in the mindset of operators, who will need to renovate their manual skills into new "joysticking" abilities. As of today, robotic-PCI is totally dependent on the operators' scrutiny and abilities. Future developments, already in course, that will add automatic and programmed features to the platform, may be able to enhance the procedure workflow by offering to interventionalists new and advanced maneuvering capabilities that may surpass manual operation in subtlety, delicacy, precision and repeatability. 


\section{Conclusions}

Introduction of robotic-assisted PCI in a tertiary center was associated with safe and effective results, comparable to predefined goals of optimal performance.

\section{Acknowledgments}

Funding: This study was partially supported by the Brazilian Program for Institutional Development of the Unified Healthcare System (PROADI-SUS) (grant number NUP: 25000.047193/2018-21).

\section{Footnote}

Reporting Checklist: The authors have completed the TREND and the MDAR reporting checklists. Available at https://cdt.amegroups.com/article/view/10.21037/cdt-21$442 / \mathrm{rc}$

Data Sharing Statement: Available at https://cdt.amegroups. com/article/view/10.21037/cdt-21-442/dss

Peer Review File: Available at https://cdt.amegroups.com/ article/view/10.21037/cdt-21-442/prf

Conflicts of Interest: All authors have completed the ICMJE uniform disclosure form (available at https://cdt.amegroups. $\mathrm{com} / \mathrm{article} / \mathrm{view} / 10.21037 / \mathrm{cdt}-21-442 /$ coif). PAL is supported in part by a grant from The National Council for Scientific and Technological Development (CNPq) Brazil (grant number 306677/2019-9). He serves as an unpaid editorial board member of Cardiovascular Diagnosis and Therapy from September 2021 to September 2022. The other authors have no conflicts of interest to declare.

Ethical Statement: The authors are accountable for all aspects of the work in ensuring that investigated and resolved. The study was conducted in accordance with the Declaration of Helsinki (as revised in 2013). The protocol was approved by the institutional review board of Hospital Israelita Albert Einstein, Sao Paulo-SP, Brazil and by the National Commission of Ethics in Research (CAAE: 96392318.4.0000.0071), Brasília-DF, Brazil. Signed, written, informed consent was obtained from every patient.

Open Access Statement: This is an Open Access article distributed in accordance with the Creative Commons
Attribution-NonCommercial-NoDerivs 4.0 International License (CC BY-NC-ND 4.0), which permits the noncommercial replication and distribution of the article with the strict proviso that no changes or edits are made and the original work is properly cited (including links to both the formal publication through the relevant DOI and the license). See: https://creativecommons.org/licenses/by-nc-nd/4.0/.

\section{References}

1. Elmaraezy A, Ebraheem Morra M, Tarek Mohammed A, et al. Risk of cataract among interventional cardiologists and catheterization lab staff: A systematic review and metaanalysis. Catheter Cardiovasc Interv 2017;90:1-9.

2. Smilowitz NR, Balter S, Weisz G. Occupational hazards of interventional cardiology. Cardiovasc Revasc Med 2013;14:223-8.

3. Durán A, Hian SK, Miller DL, et al. Recommendations for occupational radiation protection in interventional cardiology. Catheter Cardiovasc Interv 2013;82:29-42.

4. Jeans SP, Faulkner K, Love HG, et al. An investigation of the radiation dose to staff during cardiac radiological studies. Br J Radiol 1985;58:419-28.

5. Mahmud E, Naghi J, Ang L, et al. Demonstration of the Safety and Feasibility of Robotically Assisted Percutaneous Coronary Intervention in Complex Coronary Lesions: Results of the CORA-PCI Study (Complex Robotically Assisted Percutaneous Coronary Intervention). JACC Cardiovasc Interv 2017;10:1320-7.

6. Mahmud E, Schmid F, Kalmar P, et al. Feasibility and Safety of Robotic Peripheral Vascular Interventions: Results of the RAPID Trial. JACC Cardiovasc Interv 2016;9:2058-64.

7. Mangels DR, Giri J, Hirshfeld J, et al. Robotic-assisted percutaneous coronary intervention. Catheter Cardiovasc Interv 2017;90:948-55.

8. Maor E, Eleid MF, Gulati R, et al. Current and Future Use of Robotic Devices to Perform Percutaneous Coronary Interventions: A Review. J Am Heart Assoc 2017;6:006239.

9. Patel TM, Shah SC, Pancholy SB. Long Distance TeleRobotic-Assisted Percutaneous Coronary Intervention: A Report of First-in-Human Experience. EClinicalMedicine 2019;14:53-8.

10. Smilowitz NR, Moses JW, Sosa FA, et al. RoboticEnhanced PCI Compared to the Traditional Manual Approach. J Invasive Cardiol 2014;26:318-21.

11. Smitson CC, Ang L, Pourdjabbar A, et al. Safety and Feasibility of a Novel, Second-Generation RoboticAssisted System for Percutaneous Coronary Intervention: 
First-in-Human Report. J Invasive Cardiol 2018;30:152-6.

12. Lemos PA, Franken M, Mariani J Jr, et al. Robotic-assisted intervention strategy to minimize air exposure during the procedure: a case report of myocardial infarction and COVID-19. Cardiovasc Diagn Ther 2020;10:1345-51.

13. Lemos PA, Franken M, Mariani J Jr, et al. Use of robotic assistance to reduce proximity and air-sharing during percutaneous cardiovascular intervention. Future Cardiol 2021;17:865-73.

14. Garcia-Garcia HM, McFadden EP, Farb A, et al. Standardized End Point Definitions for Coronary Intervention Trials: The Academic Research Consortium-2 Consensus Document. Circulation 2018;137:2635-50.

15. Thygesen K, Alpert JS, Jaffe AS, et al. Fourth Universal Definition of Myocardial Infarction (2018). Glob Heart 2018;13:305-38.

16. Ellis SG, Ajluni S, Arnold AZ, et al. Increased coronary perforation in the new device era. Incidence, classification, management, and outcome. Circulation 1994;90:2725-30.

17. Sarno G, Lagerquist B, Olivecrona G, et al. Real-life clinical outcomes with everolimus eluting platinum chromium stent with an abluminal biodegradable polymer in patients from the Swedish Coronary Angiography and Angioplasty Registry (SCAAR). Catheter Cardiovasc Interv 2017;90:881-7.

18. Wu JW, Hu H, Li D, et al. In-hospital outcomes of delayed stenting in hemodynamically stable patients with ST-segment elevation myocardial infarction: the CCC (Care for Cardiovascular Disease in China) project. Cardiovasc Diagn Ther 2019;9:462-71.

19. Panaich SS, Arora S, Patel N, et al. Comparison of InHospital Mortality, Length of Stay, Postprocedural Complications, and Cost of Single-Vessel Versus Multivessel Percutaneous Coronary Intervention in Hemodynamically Stable Patients With ST-Segment Elevation Myocardial Infarction (from Nationwide Inpatient Sample [2006 to 2012]). Am J Cardiol 2016;118:950-8.

20. Kim MC, Hyun JY, Ahn Y, et al. Optimal Revascularization Strategy in Non-ST-Segment-Elevation Myocardial Infarction With Multivessel Coronary Artery Disease: Culprit-Only Versus One-Stage Versus Multistage Revascularization. J Am Heart Assoc 2020;9:e016575.

21. Miura T, Miyashita Y, Motoki H, et al. In-hospital clinical outcomes of elderly patients ( $\geq 80$ years) undergoing percutaneous coronary intervention. Circ J 2014;78:1097-103.

22. Heer T, Hochadel M, Schmidt K, et al. Sex Differences in Percutaneous Coronary Intervention-Insights From the Coronary Angiography and PCI Registry of the German
Society of Cardiology. J Am Heart Assoc 2017;6:004972.

23. Prado GF Jr, Ribeiro EE, Melo PH, et al. Clinical performance of a novel ultrathin strut, low-dose, sirolimuseluting stent with abluminal-only biodegradable polymeric coating for patients undergoing percutaneous coronary intervention in the daily practice. Cardiovasc Diagn Ther 2015;5:414-9.

24. Singh K, Rashid M, So DY, et al. Incidence, predictors, and clinical outcomes of early stent thrombosis in acute myocardial infarction patients treated with primary percutaneous coronary angioplasty (insights from the University of Ottawa Heart Institute STEMI registry). Catheter Cardiovasc Interv 2018;91:842-8.

25. Welt FGP, Shah PB, Aronow HD, et al. Catheterization Laboratory Considerations During the Coronavirus (COVID-19) Pandemic: From the ACC's Interventional Council and SCAI. J Am Coll Cardiol 2020;75:2372-5.

26. Kindi FA, Arafa Sel D, Arabi AR. Acute stent thrombosis. Heart Views 2014;15:133-4.

27. Hara H, Serruys PW, Takahashi K, et al. Impact of PeriProcedural Myocardial Infarction on Outcomes After Revascularization. J Am Coll Cardiol 2020;76:1622-39.

28. Lemmert ME, van Bommel RJ, Diletti R, et al. Clinical Characteristics and Management of Coronary Artery Perforations: A Single-Center 11-Year Experience and Practical Overview. J Am Heart Assoc 2017;6:007049.

29. Nairooz R, Parzynski CS, Curtis JP, et al. Contemporary Trends, Predictors and Outcomes of Perforation During Percutaneous Coronary Intervention (From the NCDR Cath PCI Registry). Am J Cardiol 2020;130:37-45.

30. Weisz G, Smilowitz NR, Metzger DC, et al. The association between experience and proficiency with robotic-enhanced coronary intervention-insights from the PRECISE multicenter study. Acute Card Care 2014;16:37-40.

31. Weisz G, Metzger DC, Caputo RP, et al. Safety and feasibility of robotic percutaneous coronary intervention: PRECISE (Percutaneous Robotically-Enhanced Coronary Intervention) Study. J Am Coll Cardiol 2013;61:1596-600.

Cite this article as: Lemos PA, Franken M, Mariani J Jr, Caixeta A, Almeida BO, Pitta FG, Prado GFA, Garzon S, Ramalho F, Albuquerque G, Gomes IM, de Oliveira IS, Valle L, Galastri L, Affonso BB, Nasser F, Garcia RG. Safety and effectiveness of introducing a robotic-assisted percutaneous coronary intervention program in a tertiary center: a prospective study. Cardiovasc Diagn Ther 2022;12(1):67-76. doi: 10.21037/ cdt-21-442 